\title{
Study on the Influence of Different Prophase Stress Levels on the Fatigue Damage Characteristics of Granite
}

\author{
Tianzuo Wang $\mathbb{D},,^{1,2}$ Mengya Xue $\mathbb{D}^{1,2}$ Peng Sha $\mathbb{D}^{1,2}$ Fei Xue $\mathbb{D}^{1,2}$ and Linxiang Wang $\mathbb{D}{ }^{1,2}$ \\ ${ }^{1}$ Key Laboratory of Rock Mechanics and Geohazards of Zhejiang Province, College of Civil Engineering, Shaoxing University, \\ Shaoxing, Zhejiang 312000, China \\ ${ }^{2}$ Zhejiang Collaborative Innovation Center for Prevention and Control of Mountain Geologic Hazards, Shaoxing, \\ Zhejiang 312000, China
}

Correspondence should be addressed to Peng Sha; shapeng@usx.edu.cn

Received 12 January 2021; Accepted 27 May 2021; Published 7 June 2021

Academic Editor: Jiaxi Zhou

Copyright $\odot 2021$ Tianzuo Wang et al. This is an open access article distributed under the Creative Commons Attribution License, which permits unrestricted use, distribution, and reproduction in any medium, provided the original work is properly cited.

\begin{abstract}
In order to reveal the influence of prophase stress levels on the fatigue damage characteristics of granite, uniaxial fatigue tests of granite with different prophase stress levels were carried out on the basis of the MTS 815.04 rock mechanics test system. The results show that, under the same number of cycles, the failure degree increases with the increase of the prophase stress level. Under the low upper limit of cyclic stress, the tangent modulus and dissipated energy increase significantly with the increase of prophase stress level at the early stage of the cycle loading, while the increasing trend is not obvious with the increase of prophase stress level at the late stage. Under the high upper limit of cyclic stress, the tangent modulus and dissipated energy are less affected by the prophase stress level. The development trend of elastic release energy is not obvious with the increase of prophase stress level, which is less affected by the number of cycles. From the damage parameters defined by dissipative energy, under the low upper limit of cyclic stress, the initial damage is less affected by the prophase stress level. With the increase of the number of cycles, the influence of the prophase stress level on the development trend of the damage variable increases gradually. And the development trend of damage variables shows "C-shaped" damage.
\end{abstract}

\section{Introduction}

Fatigue damage occurs inside the rock under cyclic loading, accompanied by the initiation and expansion process of cracks, which further affects the engineering stability [1]. In some actual engineering, rocks in different locations may be in different stress states. For example, rocks at different depths in the reservoir area are subjected to different lateral pressure from the water. Rocks at different distances from the freeing surface are subjected to different stress states during tunnel construction. High stress levels will cause structural defects in the inside of rock. Once the rock is subjected to cyclic loading, the fracture evolution process and fatigue characteristics will be affected.

In recent years, a large number of experimental studies have been carried out on the fatigue characteristics of rocks with different types of initial damage.
Mokhfi et al. [2, 3] used Acoustic Emission (AE) technology for testing and found that high temperature would lead to the formation of cracks, and the expansion of microcracks inside the rock, thus affecting the mechanical properties of the rock. Yang and $\mathrm{Hu}$ [4] studied the change of red sandstone with initial damage caused by cyclic loading at high temperature, creep, and permeability. Wang et al. [5] found that, subjected to different thermal damage, the dynamic strength and deformation capacity of granite decreased with the increase of temperature under cyclic impact load. Xia et al. $[6,7]$ conducted cyclic load tests on basalt and granite subjected to temperature and found that the peak strain of rock increased with the increase of temperature and cyclic load, while the elastic modulus showed an opposite trend. Mambou et al. [8, 9], respectively, studied the influence of high temperature on the internal damage of rock from the 
physical and mechanical properties. Li et al. [10] used MTS electrohydraulic closed-loop test system to carry out strain control cycle tests on ice saturated samples and got the conclusion that the dynamic Young's modulus increased with the increase of frequency, confining pressure, and sand content but decreased with the increase of strain and temperature. Based on damage mechanics theory, Zhu et al. [11] proposed a fatigue damage model, which can reflect temperature damage, and initial fatigue damage. Chen et al. $[7,12]$ found that the fatigue life of rock decreases with the increase of temperature, and the damage parameters have a linear relationship with the fatigue life. The above studies reveal the influence of high temperature on the fatigue damage characteristics of rock from the perspective of stress-strain characteristics and elastic modulus.

In addition, some scholars have studied the fatigue damage characteristics of rocks under different freeze-thaw conditions. Ling et al. [13] studied the influence of temperature, water content, and confining pressure on the ratio of dynamic elastic modulus and adopted the stiffness and damping ratio evolution model established by stress-strain curve to analyze the evolution law of the stiffness and damping ratio of frozen soil under long-term and low level repeated cyclic loading. Li et al. [14] studied the fatigue characteristics of frozen sandstone samples under fracture and saturation and found that, compared with unfractured and frozen sandstone samples, the fractured and frozen sandstone samples had a more obvious fatigue effect. Liu et al. $[15,16]$ found that, due to the initial microfracture and fatigue phenomenon, the moving shaft stiffness of the frozen sample decreased rapidly in the initial cycle period and gradually stabilized with the increase of the number of cycles. Wang et al. [17] conducted fatigue tests on granite after freeze-thaw treatment and found that the frost heave force generated by water-ice phase transition led to the accumulation of damage at the crack tip. Zhao et al. [18] studied the evolution law of hydraulic fracture through strain localization evolution of double-crack granite under hydraulic fracturing based on digital image correlation. Ke et al. $[19,20]$ found the internal damage of sandstone caused by freeze-thaw weathering and established a unified model to describe the deterioration of dynamic mechanical strength of rock materials during repeated freeze-thaw weathering. These results indicate that the freeze-thaw action leads to the aggravation of the internal damage of rock, which reduces the mechanical properties of rock under fatigue load.

As mentioned above, most of the researches focused on the influence of high temperature and freeze-thaw action on the fatigue damage characteristics of rock, and few researches on the fatigue damage and deformation characteristics of rock under different prophase stress states for now. In this paper, uniaxial fatigue tests of granite with different prophase stress levels were carried out on granite samples. The deformation characteristics, mechanical characteristics, and fatigue characteristics of granite are analyzed to study the influence of prophase stress level on the fatigue damage characteristics of rock.

\section{Test Equipment and Test Scheme}

2.1. Sample Preparation. The granite samples used in this experiment were taken from Tuanshan Village, Huangbai Town, Miluo City, Yueyang City, Hunan Province. The samples were drilled from the same block and cut into cylinders with a diameter of $50 \mathrm{~mm}$ and a length of $100 \mathrm{~mm}$. They were prepared in strict accordance with the standards of the International Society for Rock Mechanics (ISRM). In addition, the deviation is controlled within $0.5 \mathrm{~mm}$, and the nonparallelism of the end face is less than $0.03 \mathrm{~mm}$, as shown in Figure 1. X-ray diffraction phase analysis shows that samples mainly contain quartz $(0.4 \%)$, biotite $(23.8 \%)$, albite (7.1\%), microcline (47.6\%), and orthoclase $(16.1 \%)$, as shown in Figure 2. The average density of the samples is $2.62 \mathrm{~g} / \mathrm{cm}^{3}$ and longitudinal wave velocity is between $3240 \mathrm{~m} / \mathrm{s}$ and $3320 \mathrm{~m} / \mathrm{s}$, which can be used to ensure the uniformity of the samples and the reliability of the test results.

2.2. Experiment Equipment and Test Scheme. The MTS 815.04 rock mechanics test system was used to conduct the fatigue test, which is composed of hydraulic pump, host, servo control unit, and data acquisition unit, as shown in Figure 3. Its stiffness reaches $10.5 \times 10^{9} \mathrm{~N} / \mathrm{m}$, and the maximum axial force is $4600 \mathrm{kN}$. Three sets of uniaxial cyclic load tests under different prophase stress levels were carried out on the system. In addition, three different upper cyclic stress limits were set under the same prophase stress level to analyze whether the fatigue damage characteristics of granite under different prophase stress levels show similar laws under different upper limit of cyclic stress. The scheme is shown in Table 1. In this paper, the fatigue damage characteristics of granite are mainly studied at the fatigue initial stage, which only accounts for a small part of the whole cycle process. So, the cyclic period of all specimens is set as 300 cycles. The axial displacement control method with a rate of $0.001 \mathrm{~mm} / \mathrm{s}$ is firstly used to load to a certain stress level (the prophase stress level), and then the force was unloaded to the lower limit of cyclic stress $10 \mathrm{MPa}$; after that, the cyclic load test stage was entered. The loading waveform was sine wave, with $1 \mathrm{~Hz}$ as the loading frequency. The test was stopped after 300 cycles in each group at last. The stress path is shown in Figure 4.

\section{Experimental Results and Analysis}

3.1. Stress-Strain Characteristics. Under the same upper limit of cyclic stress, the stress-strain curve shape is affected by the prophase stress level. The upper limit of cyclic stress $125 \mathrm{MPa}$ is taken as an example, as shown in Figure 5. The results show that when the load is applied to the prophase stress level, the relative strain gradually increases with the increase of the prophase stress level. For example, when the prophase stress level is $125 \mathrm{MPa}, 130 \mathrm{MPa}$, and $135 \mathrm{MPa}$, the relative strain is $0.002770,0.00295$, and 0.00302 , respectively. It can be seen that the internal defects of the rock samples gradually increase with the increase of the prophase stress level. In the cyclic loading stage, the stress-strain 


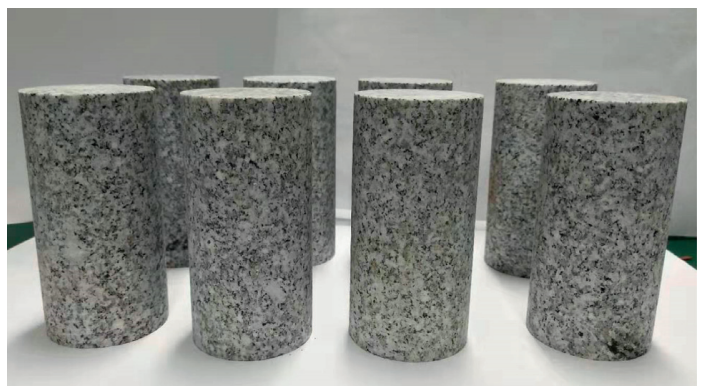

FIgURE 1: Granite samples.

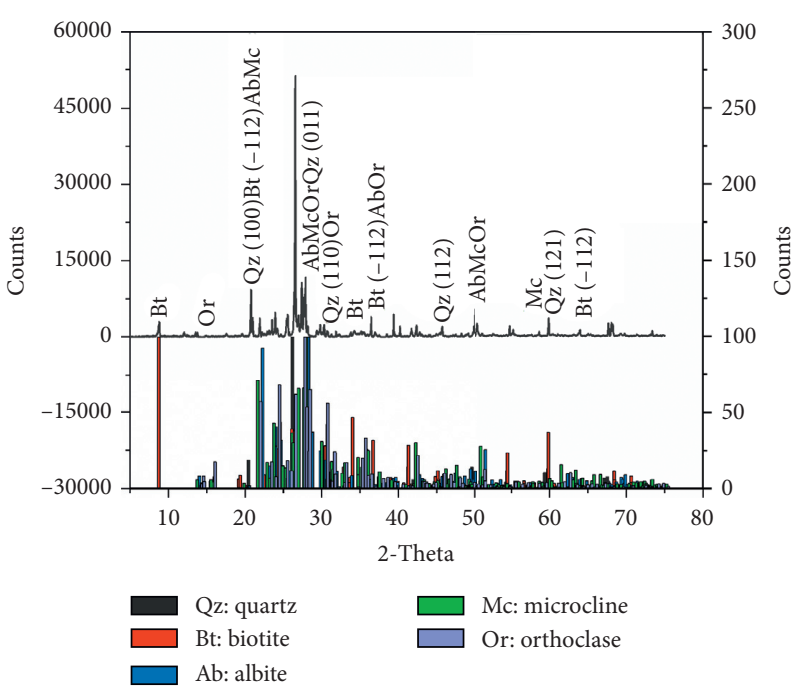

(a)



(b)

FIgURE 2: X-ray pattern (a) and chemical analysis of the granite (b).

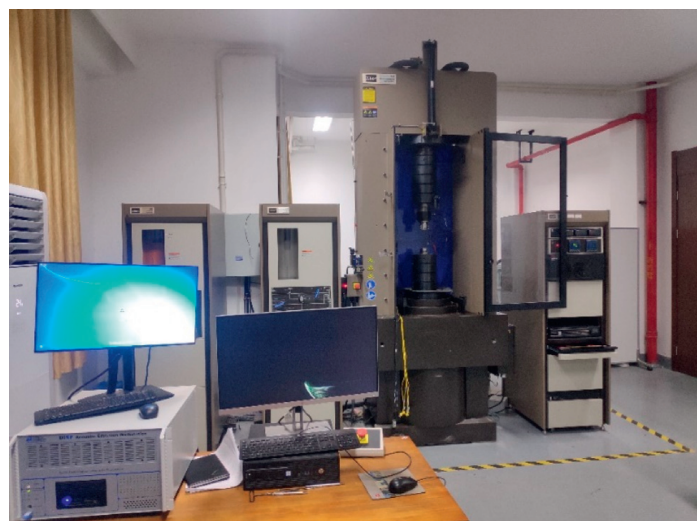

FIGURE 3: MTS 815.04 rock mechanics test system.

TABLE 1: The sample loading scheme.

\begin{tabular}{|c|c|c|c|c|}
\hline Groups & Specimens & Prophase stress level (MPa) & Upper limit of cyclic stress (MPa) & Cycles \\
\hline \multirow{3}{*}{ Group 1} & G1-C1 & \multirow{3}{*}{125} & 105 & \multirow{3}{*}{300} \\
\hline & G1-C2 & & 115 & \\
\hline & G1-C3 & & 125 & \\
\hline \multirow{3}{*}{ Group 2} & G2-C1 & \multirow{3}{*}{130} & 105 & \multirow{3}{*}{300} \\
\hline & G2-C2 & & 115 & \\
\hline & G2-C3 & & 125 & \\
\hline \multirow{3}{*}{ Group 3} & G3-C1 & \multirow{3}{*}{135} & 105 & \multirow{3}{*}{300} \\
\hline & G3-C2 & & 115 & \\
\hline & G3-C3 & & 125 & \\
\hline
\end{tabular}




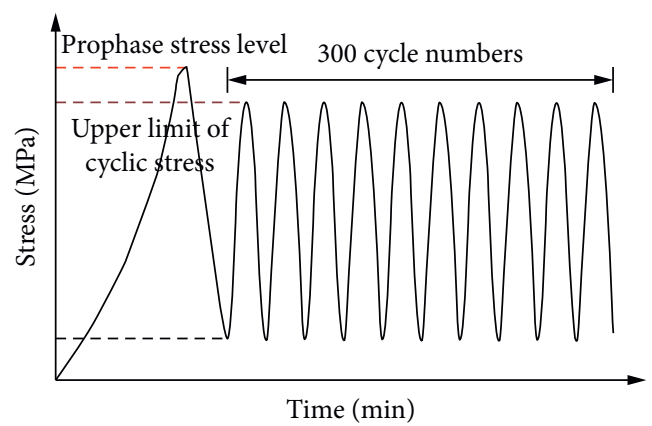

Figure 4: Schematic diagram of stress path.


G1-C3

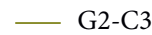

(a)

(b)

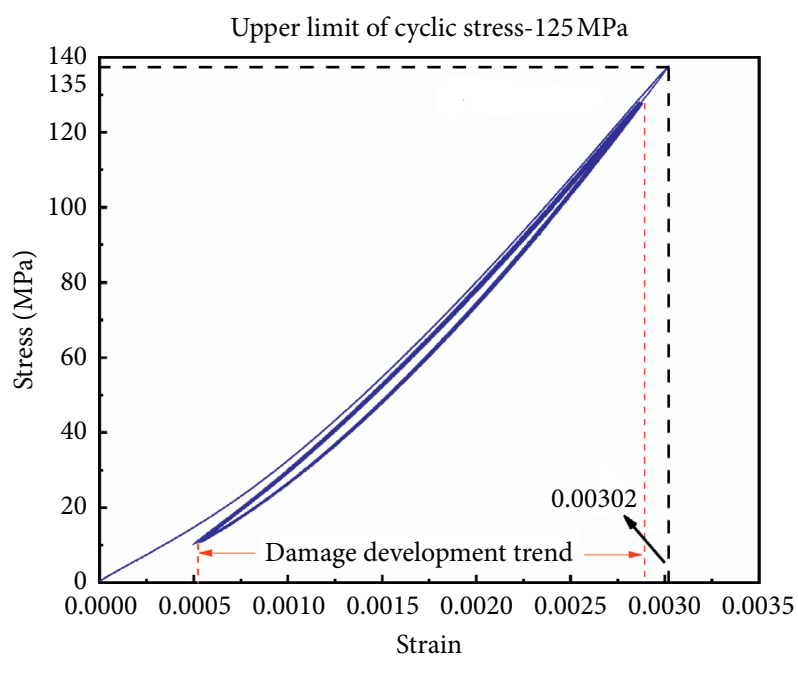

- G3-C3

(c)

FiguRE 5: Stress-strain curves of rock samples under different prophase stress levels with the same upper limit cyclic stress. (a) Prophase stress level $125 \mathrm{MPa}$. (b) Prophase stress level $130 \mathrm{MPa}$. (c) Prophase stress level $135 \mathrm{MPa}$. 
curves of the rock under cyclic loading all show an obvious periodic hysteretic cycle evolution trend, and the evolution trend is relatively intensive. The lower limit strain of the initial hysteresis loop and the upper limit strain of the last hysteresis loop gradually become farther from the origin with the increase of the prophase stress level. It indicates that the fatigue damage degree of rock gradually increases.

\subsection{Elastic Modulus}

3.2.1. Evolution Law of Elastic Modulus with Prophase Stress Level. Elastic modulus is one of the important mechanical properties of rock, which reflects the ability of rock to resist deformation. With the increase of elastic modulus, the stiffness increases gradually, and the rock is harder to deform. Because of the damage caused by the loading of the rock mass, the loading and unloading curves do not coincide, which form a hysteresis loop. The elastic modulus of the loading section is defined by the slope of the OA section on the stress-strain curve at the loading stage, which is the tangent modulus, as shown in Figure 6.

In order to explore the influence of the prophase stress level on the tangent modulus, the relation diagram between tangent modulus and the prophase stress level under different cycle times in the loading process was drawn, as shown in Figure 7.

On the one hand, tangent modulus generally presents an upward trend with the increase of the prophase stress level. That is because, before the cyclic loading, the closure degree of internal microcracks is different under different prophase stress levels. With the increase of prophase stress level, the degree of microcracks closing increases, and the deformation trend decreases. As a result, the tangent modulus increases with the increase of the prophase stress level.

On the other hand, tangent modulus shows different development trends with the increase of the prophase stress level under different upper limit of cyclic stress. Under the low upper limit of cyclic stress, the tangent modulus in the first cycle increases significantly with the increase of prophase stress levels. With the increase of the number of cycles, the development trend of tangent modulus is gradually stable. On the contrary, the tangent modulus tends to be stable in the whole cycle under the high upper limit of cyclic stress. The samples generally experience the initial fatigue stage, the constant velocity stage, and the acceleration stage in the whole cycle process, and the tangent modulus shows the same trend. Under the low upper limit of cyclic stress, because the work done by external force on samples is small, the rock samples go through the initial stage of fatigue, resulting in a long process from compaction to stability of the microcrack inside the samples. It can be conducted that different prophase stress levels in the early stage of cyclic load test have a great influence on the tangent modulus. With the increase of the number of cycles, the crack of rock under cyclic load gradually compresses and tends to a stable state into the constant velocity stage, and the elastic modulus also enters a stable state, while, under the high upper limit of cyclic stress, the external force does more work on the



FIgURE 6: Schematic diagram of tangent modulus of loading section.

samples, which leads to the short compaction stage of the microcracks inside the samples and quickly enters the stable state. The results show that the prophase stress level has little effect on the tangent modulus under the high upper limit of cyclic stress.

It can be drawn that, with the increase of the number of cycles, the tangent modulus at the same prophase stress level gradually increases. The tangent modulus under the first two cyclic loads increases greatly, but the increase is not obvious after that. That is, the newly generated damage from the third cycle is extremely small.

\subsubsection{Evolution Law of Development Trend. According to} the variation trend of tangent modulus with prophase stress level in the same number of cycles as shown in Figure 5, $k$ value is introduced to represent the slope of elastic modulus changing with the increase of prophase stress level in the same number of cycles. After fitting, the relationship between $k$ and the number of cycles is established. Under the same upper limit of cyclic stress, the relationship between the development trend $k$ value and the number of cycles is plotted, as shown in Figure 8. In order to explore the relationship between the change trend of tangent modulus and the number of cycles under the same upper limit of cyclic stress, the development law of $k$ value under different cyclic stress limit is analyzed.

It can be clearly observed that the development trend presents an inversely proportional relationship under different upper limit of cyclic stress. The development trend is gradually stable with the increase of upper limit of cyclic stress. Moreover, the inverse function is used to fit the development trend $k$ value, of which the fitting degree is high. The function can describe the development trend of rock elastic modulus with the change of prophase stress level under different cycles well.

Therefore, it can be inferred that the influence of prophase stress level on tangent modulus decreases with the increase of the upper limit of cyclic stress. Under the low upper limit of cyclic stress, the tangent modulus is greatly affected by the prophase stress level at the early stage of the 


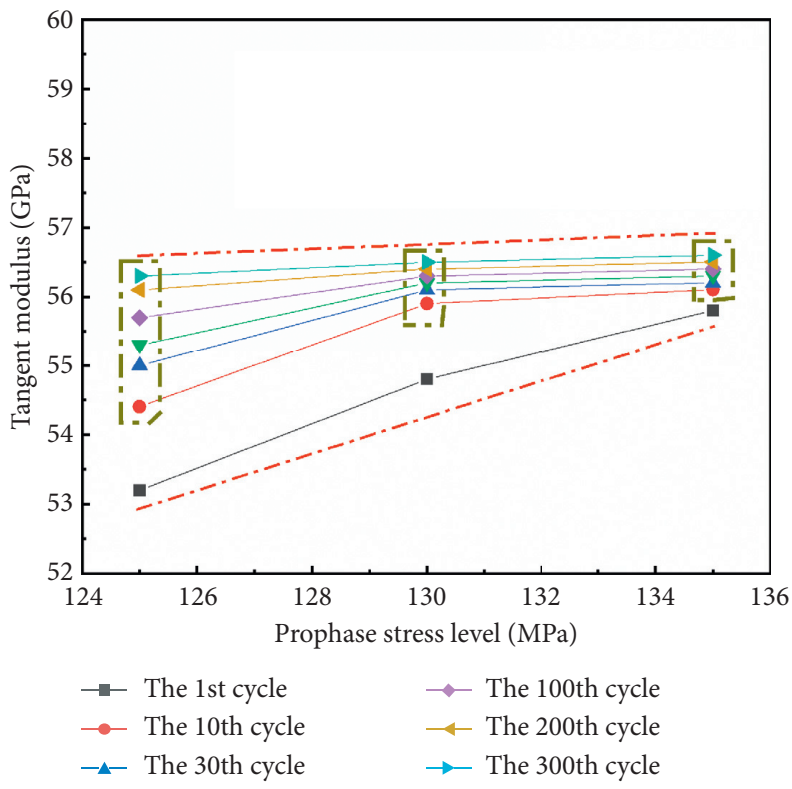

(a)

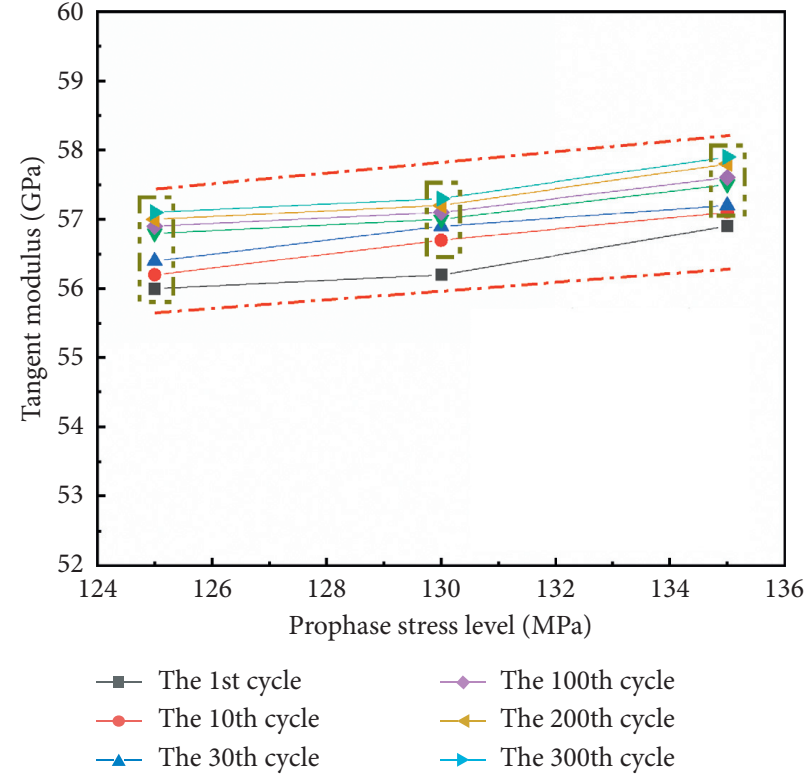

(b)

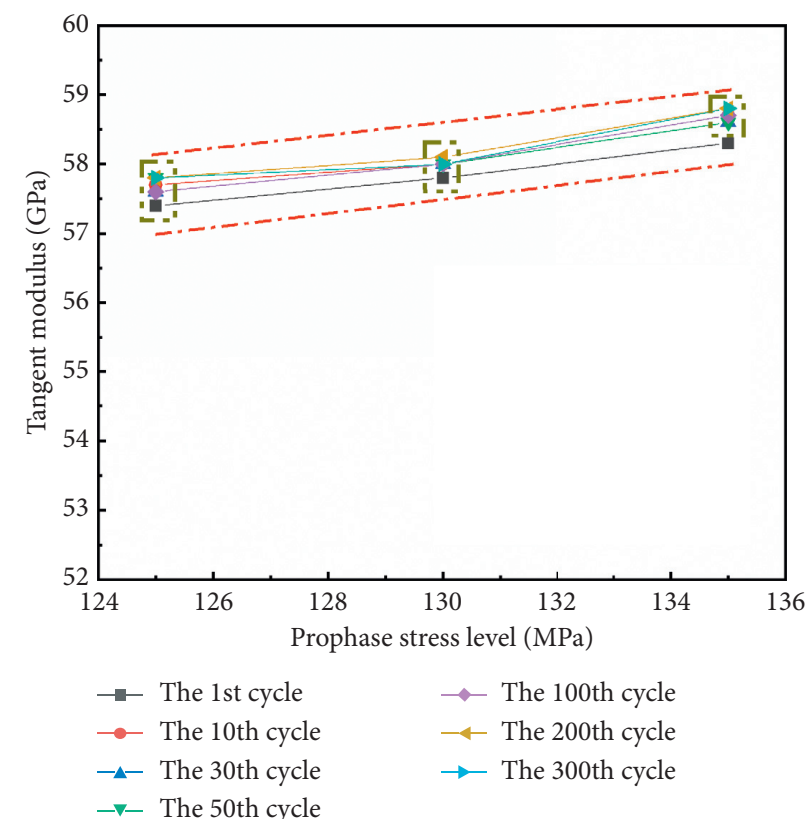

(c)

FIGURE 7: The relationship between tangent modulus and prophase stress level in the loading process. (a) Upper limit of cyclic stress $105 \mathrm{MPa}$. (b) Upper limit of cyclic stress $115 \mathrm{MPa}$. (c) Upper limit of cyclic stress $125 \mathrm{MPa}$.

cycle. On the contrary, the prophase stress level has little influence on the elastic modulus under the high upper limit of cyclic stress.

\subsection{Dissipated Energy}

3.3.1. Energy Composition. Energy dissipation of rock is the essential property of rock deformation and failure. It reflects the continuous closure of microscopic defects in rock itself, such as microcracks and holes, the development and evolution of new cracks, and the continuous weakening and final loss of material strength.

In the process of rock deformation and failure, material and energy are always exchanged with the outside world, and the deformation and failure can be regarded as the damage evolution process of energy dissipation [21]. Therefore, the mechanical response characteristics of rock can be discussed and explained from the perspective of energy. In the loading process, it is assumed that there is no energy exchange between the test system and the outside world. In addition, 


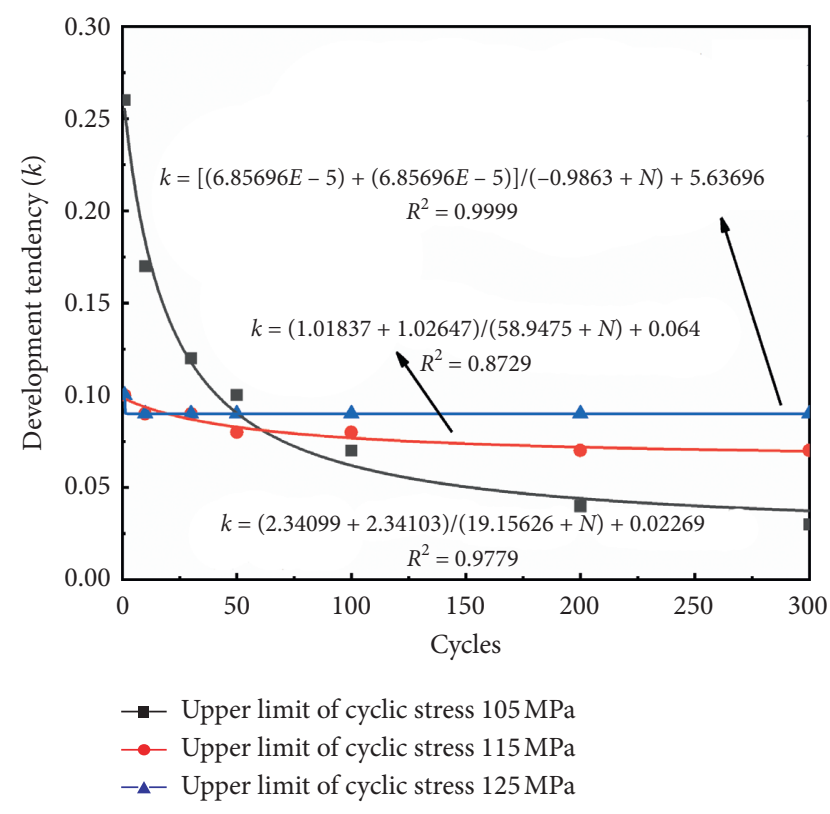

Figure 8: The relationship between $k$ value of development tendency and cycles under the same upper limit of cyclic stress.

the total work done by the external force is only converted into the elastic released energy stored in the rock and the dissipated energy consumed in the stress process. The formula is as follows:

$$
U=U^{d}+U^{e}
$$

where $U$ is the total work done by external force on the rock in the test; $U^{d}$ is expressed as dissipated energy; $U^{e}$ is expressed as elastic release energy.

Combined with the test conditions of uniaxial cyclic load, the energy distribution under cyclic load is shown in Figure 9. Dissipated energy $U^{d}$ is represented by the area enclosed by the loading curve, unloading curve, and strain axis. Elastic release energy $U^{e}$ is represented by the unloading curve, the area enclosed by the vertical line of maximum strain $\varepsilon^{\prime}$ and the strain axis.

Therefore, the dissipated energy and elastic release can be calculated by integral:

$$
\begin{aligned}
U^{d} & =\int_{0}^{\varepsilon^{\prime}} \sigma \mathrm{d} \varepsilon-\int_{\varepsilon^{\prime \prime}}^{\varepsilon^{\prime}} \sigma \mathrm{d} \varepsilon, \\
U^{e} & =\int_{\varepsilon^{\prime \prime}}^{\varepsilon^{\prime}} \sigma \mathrm{d} \varepsilon .
\end{aligned}
$$

\subsubsection{Evolutionary Process of Elastic Release Energy.} Figure 10 shows that the curve of elastic release energy changes with the prophase stress level under the same upper limit of cyclic stress and the same number of cycles, and the relative data are listed in Table 2 . It can be seen that the elastic release energy changes little with the increase of the prophase stress level, and its development trend keeps the same almost with the increase of the number of cycles. The reason is that the elastic released energy is the energy

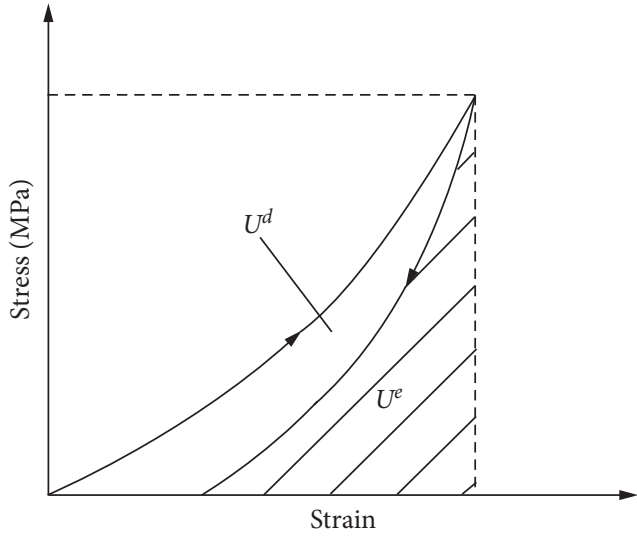

FIgURE 9: Distribution of elastic energy and dissipated energy of loaded rock units.

accumulated in the samples during elastic deformation and released during unloading. The development trend is mainly related to the elastic properties of the rock. It indicates that the samples exhibit similar elastic properties under different prophase stress levels. Therefore, it can be inferred that the prophase stress level has little effect on the elastic release energy, and it is less affected by the number of cycles either.

3.3.3. Evolution Process of Dissipative Energy. Figure 11 shows the variation curve of dissipated energy with the prophase stress level under the same upper limit of cyclic stress and the same number of cycles. It can be found that dissipative energy increases with the increase of the prophase stress level. The reason is that the rock samples experienced different prophase stress levels before cyclic loading, resulting in different development trends of internal microcracks. With the increase of the prophase stress level, the development trend of microcracks gradually increases, and the energy released by overcoming the friction between internal particles increases too. That is, the dissipated energy increases with the increase of the prophase stress level.

Moreover, dissipation energy shows different trends under different upper limits of cyclic stress. Under the low upper limit of cyclic stress $(105 \mathrm{MPa})$, the trend of dissipation energy in the first cycle is the most obvious with the increase of the prophase stress level. And then, with the increase of cycles, the trend of dissipation energy tends to be stable. On the contrary, under the high upper limit of cyclic stress $(125 \mathrm{MPa})$, the dissipated energy basically keeps a stable development trend with the increase of the prophase stress level. That is because, under the low upper limit of cyclic stress, the external force does less work on the rock samples. And the rock goes through the initial fatigue stage, during which the microcracks are constantly compacted. It means that different prophase stress levels in the early stage of cyclic load test have a great influence on the dissipated energy. With the increase of the number of cycles, the development trend of microcracks under cyclic load gradually tends to be stable, while the influence of the prophase stress level is also gradually weakened, while, under the high upper limit of cyclic stress, the external force does more work on 


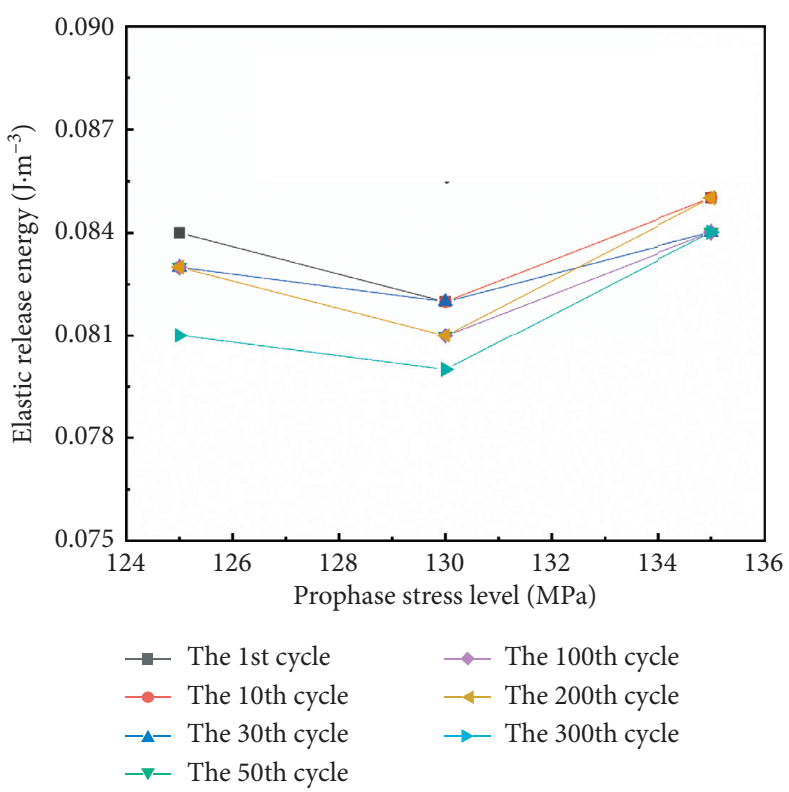

(a)

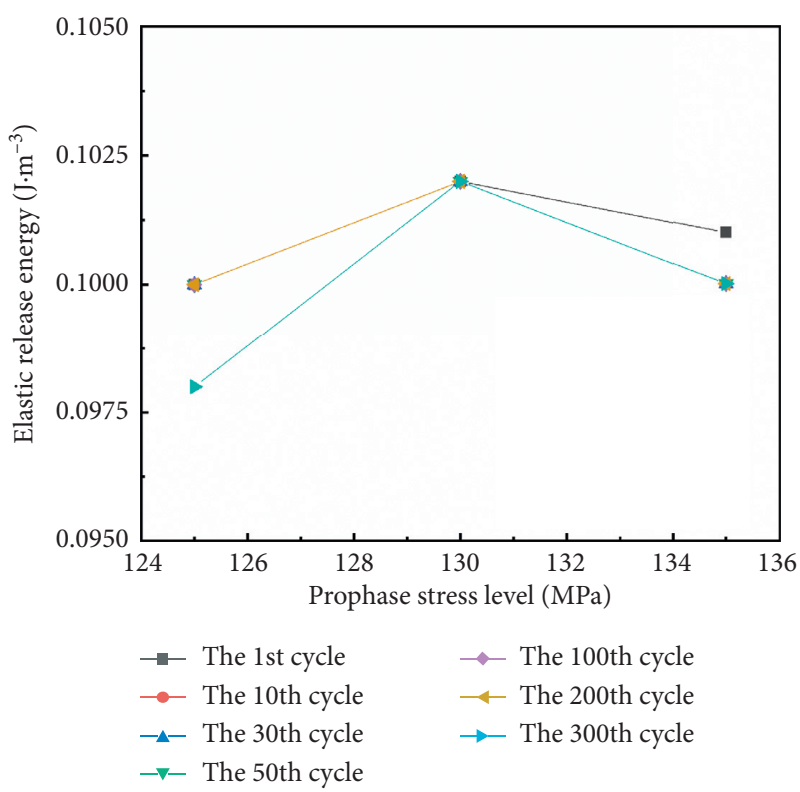

(b)

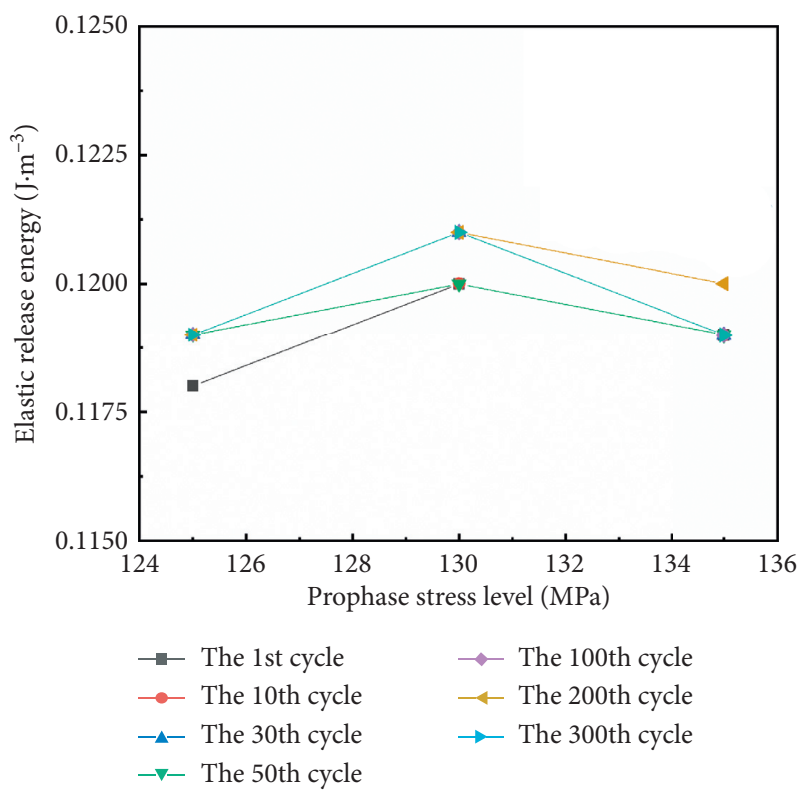

(c)

FIGURE 10: The relationship between elastic energy and prophase stress level. (a) Upper limit of cyclic stress $105 \mathrm{MPa}$. (b) Upper limit of cyclic stress $115 \mathrm{MPa}$. (c) Upper limit of cyclic stress $125 \mathrm{MPa}$.

the samples, so that the microcracks close quickly and tend to a stable state. It indicates that the dissipated energy is less affected by the prophase stress level.

Therefore, it can be inferred that the influence of the prophase stress level on the dissipated energy decreases with the increase of the upper limit of cyclic stress. Under cyclic loading with a low-stress upper limit, the dissipated energy is greatly affected by the prophase stress level in the early period of cycle. On the contrary, under cyclic loading with a high-stress upper limit, the influence of prophase stress level on dissipated energy is small.
3.4. Damage Parameters. The damage of rock and other materials under external load requires energy consumption, which means that the damage of materials and energy consumption are synchronous, and both are irreversible. On this basis, Jin et al. [22] put forward that energy dissipation could be used to define the damage variable of rock. The following formula can be used to calculate the damage parameters based on energy dissipation:

$$
D=\frac{U_{i}^{d}}{U},
$$


TABLE 2: The relative data for the elastic release energy.

\begin{tabular}{|c|c|c|c|c|c|c|c|c|c|}
\hline \multirow{4}{*}{ Number of cycles } & \multicolumn{9}{|c|}{ Elastic release energy $\left(\mathrm{J} \cdot \mathrm{m}^{-3}\right)$} \\
\hline & \multicolumn{3}{|c|}{$\begin{array}{c}\text { Upper limit of cyclic stress } \\
105 \mathrm{MPa}\end{array}$} & \multicolumn{3}{|c|}{$\begin{array}{c}\text { Upper limit of cyclic stress } \\
115 \mathrm{MPa}\end{array}$} & \multicolumn{3}{|c|}{$\begin{array}{l}\text { Upper limit of cyclic stress } \\
125 \mathrm{MPa}\end{array}$} \\
\hline & \multicolumn{3}{|c|}{ Prophase stress level (MPa) } & \multicolumn{3}{|c|}{ Prophase stress level (MPa) } & \multicolumn{3}{|c|}{ Prophase stress level (MPa) } \\
\hline & 125 & 130 & 135 & 125 & 130 & 135 & 125 & 130 & 135 \\
\hline 1 st & 0.084 & 0.100 & 0.118 & 0.082 & 0.102 & 0.120 & 0.085 & 0.101 & 0.119 \\
\hline 10th & 0.083 & 0.100 & 0.119 & 0.082 & 0.102 & 0.120 & 0.085 & 0.100 & 0.119 \\
\hline 30th & 0.083 & 0.100 & 0.119 & 0.082 & 0.102 & 0.121 & 0.084 & 0.100 & 0.119 \\
\hline 50th & 0.083 & 0.100 & 0.119 & 0.081 & 0.102 & 0.120 & 0.084 & 0.100 & 0.119 \\
\hline 100th & 0.093 & 0.100 & 0.119 & 0.081 & 0.102 & 0.121 & 0.084 & 0.100 & 0.119 \\
\hline 200th & 0.083 & 0.100 & 0.119 & 0.081 & 0.102 & 0.121 & 0.085 & 0.100 & 0.119 \\
\hline 30th & 0.081 & 0.098 & 0.119 & 0.080 & 0.102 & 0.121 & 0.084 & 0.100 & 0.119 \\
\hline
\end{tabular}

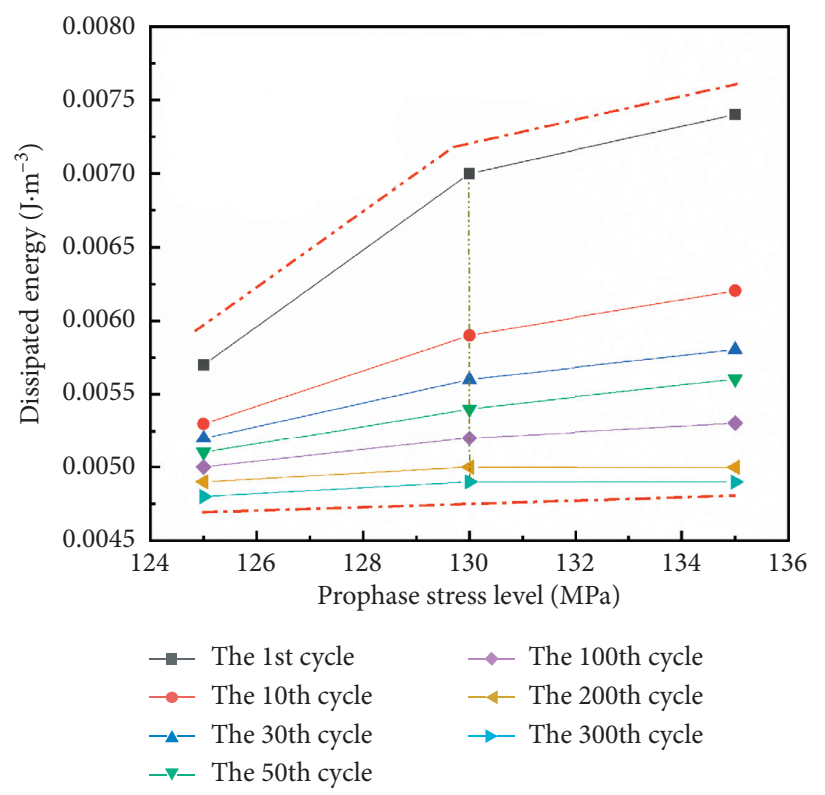

(a)

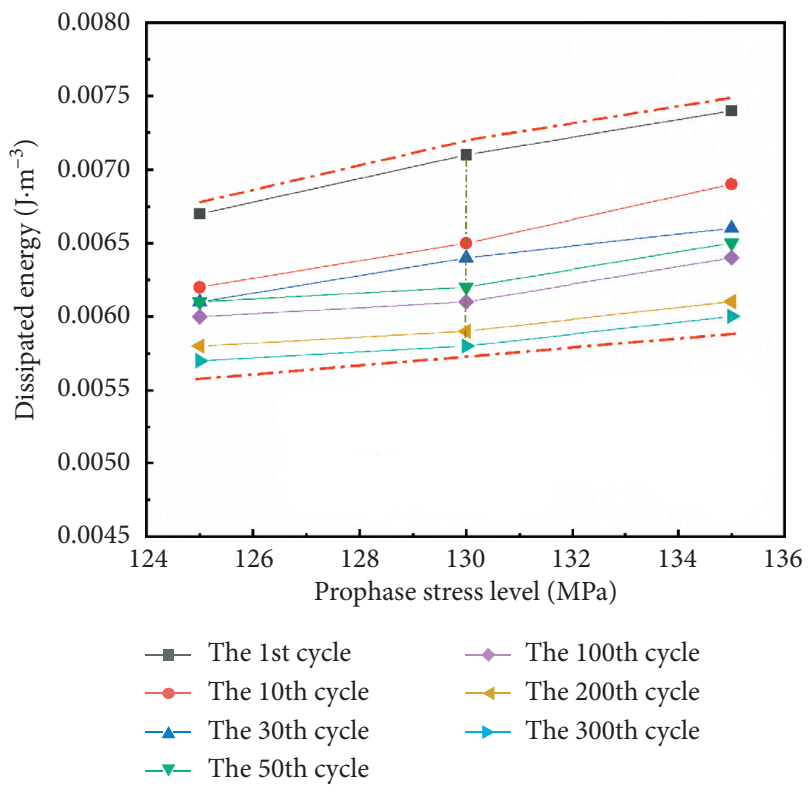

(b)

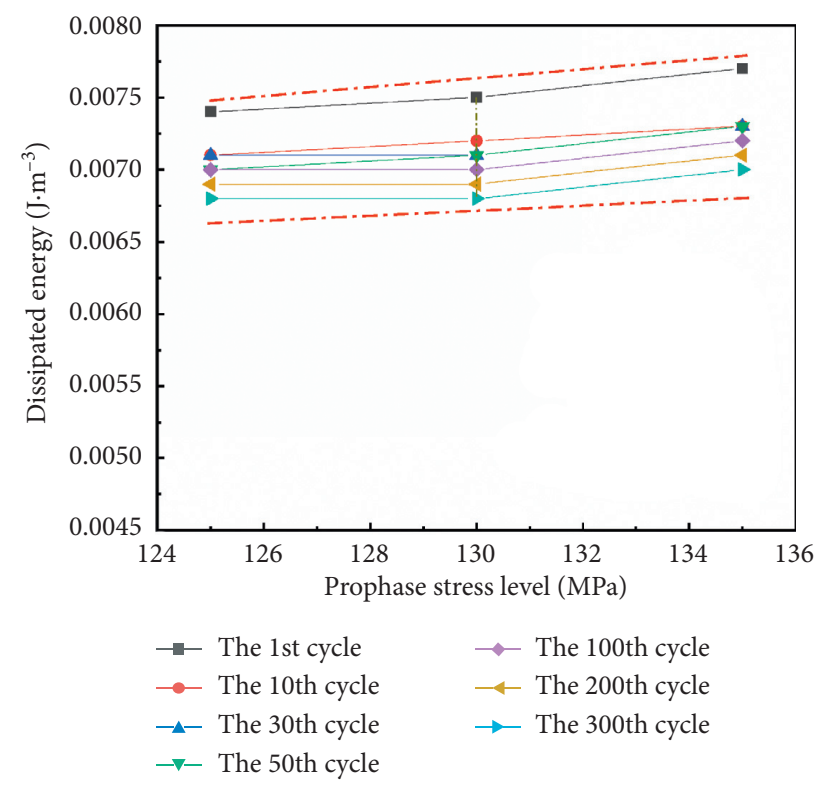

(c)

Figure 11: The relationship between dissipated energy and prophase stress level. (a) Upper limit of cyclic stress $105 \mathrm{MPa}$. (b) Upper limit of cyclic stress $115 \mathrm{MPa}$. (c) Upper limit of cyclic stress $125 \mathrm{MPa}$. 




(a)

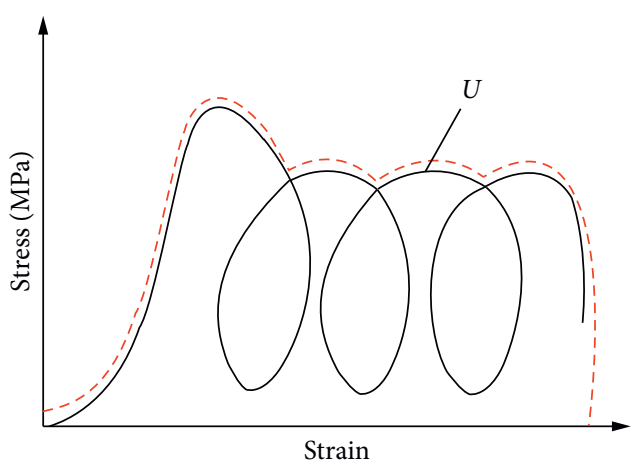

(b)

FIgURE 12: Calculation of constitutive energy and dissipation energy.

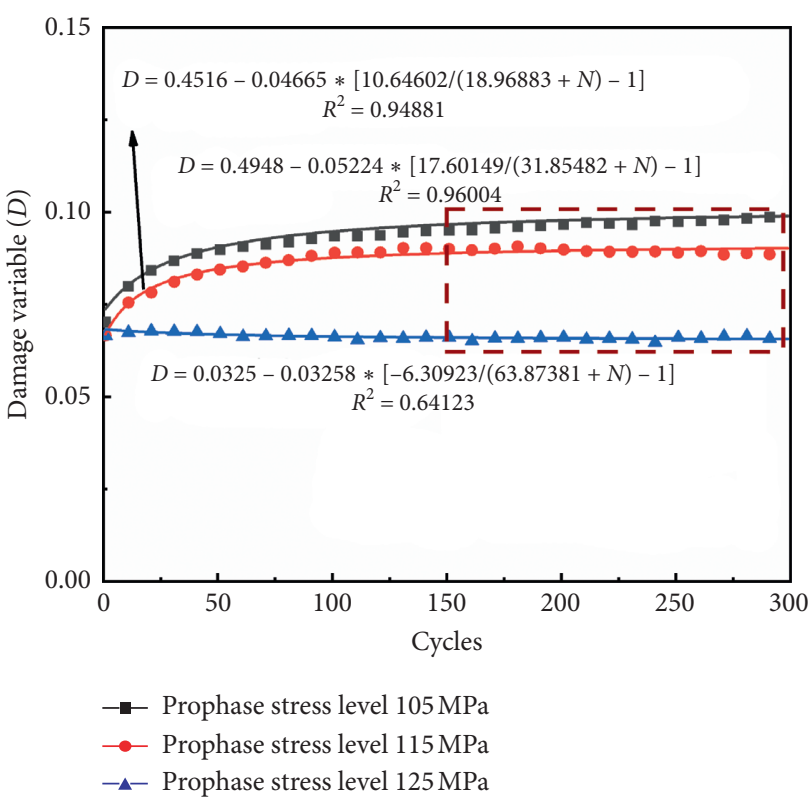

(a)



(b)



(c)

Figure 13: The relationship between the damage variable and cycles under different prophase stress levels. (a) Upper limit of cyclic stress $105 \mathrm{MPa}$. (b) Upper limit of cyclic stress $115 \mathrm{MPa}$. (c) Upper limit of cyclic stress $125 \mathrm{MPa}$. 
where $D$ is the damage variable; $U_{i}^{d}$ is the dissipated energy in week $i$, calculated by the cumulative area enclosed by the stress-strain curve of cycle $i$; $U$ is the constitutive energy in the test process, calculated by the area enclosed by the stress-strain curve in the whole process. It is shown in Figure 12.

Figure 13 shows the relationship between the damage parameters and the number of cycles under different prophase stress states. Under different prophase stress levels, the initial damage variables of rock samples remain in the range of $0.05 \sim 0.09$. In addition, the development trend of damage variables is $\mathrm{C}$-shaped damage curve, which is similar to the conclusion in the literature [23]. C-shaped damage curve shows that when the maximum stress is lower than the endurance limit of the rock, the irreversible deformation remains stable for a long time after the initial stage, and there is no acceleration stage. Based on the inverse function of Xiao et al. [23] for fitting, as in equation (4), the formula is calculated with a high fitting degree. It indicates that the model can reflect the trend of damage variables under the different prophase stress levels well.

$$
D=A-B \cdot\left(\frac{C}{E+N}-1\right),
$$

where $D$ is damage variable; $A, B, C, E$ are fitting constants.

The difference of the initial damage variable is small at different prophase stress levels, indicating that the prophase stress level has little influence on the initial damage of rock. Under the low upper limit of cyclic stress, the development trend of damage variable gradually increases with the increase of the number of cycles. And it tends to be stable after 150 cycles. On the contrary, under the high upper limit of cyclic stress, the damage variable basically stays stable with the increase of cyclic numbers. It can be inferred that, with the increase of prophase stress levels, the variation trend of the damage variable decreases gradually.

\section{Conclusion}

As a kind of heterogeneous and complex geological material, different parts of rock mass are in different initial stress states. In this paper, uniaxial cyclic loading tests of granite under different prophase stress levels were carried out. The impact of prophase stress level on the fatigue damage characteristics of granite samples is investigated from the perspectives of stress-strain curve characteristics, tangent modulus of loading section, energy characteristics, and damage parameters. The following conclusions can be drawn based on the test results.

(1) By studying the stress-strain curves of the same upper limit of cyclic stress under different prophase stress levels, it is found that the strain is greatly affected by the prophase stress levels. Before the cyclic loading, the rock samples deformation increases with the increase of the prophase stress level. In addition, during the cycle, the damage deformation gradually increases with the increase of the prophase stress level.
(2) Through the study on the influence of different prophase stress levels on tangent modulus, it is shown that the influence of prophase stress levels on tangent modulus is more obvious. Especially, under the cyclic loading with a low-stress upper limit, the elastic modulus is greatly affected by the prophase stress level at the early stage of the cycle. On the contrary, under the cyclic loading of a high-stress upper limit, the influence of the prophase stress level is small. In addition, this paper introduces the development trend $k$ value and finds that this value is approximately inversely proportional to the number of cycles. It can reflect the development trend of rock elastic modulus changing with the prophase stress level under different cycles well.

(3) Through the study of energy characteristics, it is found that the influence of the prophase stress level on dissipated energy is smaller with the increase of the upper limit of cyclic stress. Under a low upper limit of cyclic stress, the dissipation energy is markedly affected by the prophase stress level in the early stage of the cycle, whereas it is less affected by prophase stress level in the high upper limit of cyclic stress.

(4) Through the damage parameters defined based on the energy dissipated energy, it is found that the initial damage variable is less affected by the prophase stress level. But, with the increase of the number of cycles, the prophase stress level has a more obvious influence on the changing trend of the damage variable. That is, with the increase of the prophase stress level, the damage variable tends to be stable with the increase of the number of cycles.

\section{Data Availability}

The data used to support the findings of this study are included within the article.

\section{Conflicts of Interest}

The authors declare that they have no conflicts of interest.

\section{Acknowledgments}

The authors would like to acknowledge the financial support for this study supported by the Second Tibetan Plateau Scientific Expedition and Research Program (grant no. 2019QZKK0904), the National Natural Science Foundation of China (grant no. 42007254 and 41831290), the Natural Science Foundation of Zhejiang Province (grant no. LQ20E080006), and the General Research Project of Zhejiang Education Department (grant no. Y202043108).

\section{References}

[1] C. D. Martin, P. K. Kaiser, and R. Christiansson, "Stress, instability and design of under-ground excavations," 
International Journal of Rock Mechanics and Mining Sciences, vol. 40, no. 7-8, pp. 1027-1047, 2003.

[2] T. Mokhfi, P. William, and S. Rafat, "Damage in granite under heating/cooling cycles and water freeze-thaw condition," International Journal of Rock Mechanics \& Mining Sciences, vol. 45, no. 7, pp. 1164-1175, 2008.

[3] G. Viktoria, J. Michael, R. Andreas, and E. Tschegg, "Effects of thermal-heating cycle treatment on thermal expansion behavior of different building stones," International Journal of Rock Mechanics and Mining Sciences, vol. 64, pp. 228-235, 2013.

[4] S.-Q. Yang and B. Hu, "Creep and long-term permeability of a red sandstone subjected to cyclic loading after thermal treatments," Rock Mechanics and Rock Engineering, vol. 51, no. 10, pp. 2981-3004, 2018.

[5] P. Wang, T. Yin, X. Li, S. Zhang, and L. Bai, "Dynamic properties of thermally treated granite subjected to cyclic impact loading," Rock Mechanics and Rock Engineering, vol. 52, no. 4, pp. 991-1010, 2019.

[6] C.-C. Xia, S.-W. Zhou, P.-Y. Zhang, Y.-S. Hu, and Y. Zhou, "Strength criterion for rocks subjected to cyclic stress and temperature variations," Journal of Geophysics and Engineering, vol. 12, no. 5, pp. 753-763, 2015.

[7] Y.-L. Chen, J. Ni, W. Shao, and R. Azzam, "Experimental study on the influence of temperature on the mechanical properties of granite under uni-axial compression and fatigue loading," International Journal of Rock Mechanics and Mining Sciences, vol. 56, pp. 62-66, 2012.

[8] L. L. N. Mambou, J. Ndop, and J.-M. B. Ndjaka, "Modeling and numerical analysis of granite rock specimen under mechanical loading and fire," Journal of Rock Mechanics and Geotechnical Engineering, vol. 7, no. 1, pp. 101-108, 2015.

[9] C. Inserra, S. Biwa, and Y. Chen, "Influence of thermal damage on linear and nonlinear acoustic properties of granite," International Journal of Rock Mechanics and Mining Sciences, vol. 62, pp. 96-104, 2013.

[10] J. C. Li, G. Y. Baladi, and O. B. Andersland, "Cyclic triaxial tests on frozen sand," Developments in Geotechnical Engineering, vol. 13, no. 1-4, pp. 233-246, 1979.

[11] Y. L. Zhu, J Yu, Y. Y. Cai, X. Tang, W. Yao, and X. Y. Liu, “A novel fatigue damage model of rock considering temperature effects," Advances in Civil Engineering, vol. 2020, Article ID 8838335, 11 pages, 2020.

[12] S. Ren, Y.-m. Bai, J.-P. Zhang, D.-y. Jiang, and C.-h. Yang, "Experimental investigation of the fatigue properties of salt rock," International Journal of Rock Mechanics and Mining Sciences, vol. 64, pp. 68-72, 2013.

[13] X.-z. Ling, Z.-y. Zhu, F. Zhang et al., "Dynamic elastic modulus for frozen soil from the embankment on Beiluhe basin along the Qinghai-Tibet railway," Cold Regions Science and Technology, vol. 57, no. 1, pp. 7-12, 2009.

[14] N. Li, P. Zhang, Y. Chen, and G. Swoboda, "Fatigue properties of cracked, saturated and frozen sandstone samples under cyclic loading," International Journal of Rock Mechanics and Mining Sciences, vol. 40, no. 1, pp. 145-150, 2003.

[15] E. L. Liu, Y. M. Lai, M. K. Liao, X. Y. Liu, and F. Hou, "Fatigue and damage properties of frozen silty sand samples subjected to cyclic triaxial loading," Canadian Geotechnical Journal, vol. 53, pp. 1883-1901, 2016.

[16] J. Park, C.-U. Hyun, and H.-D. Park, "Changes in microstructure and physical properties of rocks caused by artificial freeze-thaw action," Bulletin of Engineering Geology and the Environment, vol. 74, no. 2, pp. 555-565, 2015.
[17] Y. Wang, J. Q. Han, and C. H. Li, “Acoustic emission and CT investigation on fracture evolution of granite containing two flaws subjected to freeze-thaw and cyclic uniaxial increasingamplitude loading conditions," Construction and Building Materials, vol. 260, no. 10, pp. 1-14, 2020.

[18] C. Zhao, J. Q. Xing, Y. M. Zhou, Z. M. Shi, and G. Wang, "Experimental investigation on hydraulic fracturing of granite specimens with double flaws based on DIC," Engineering Geology, vol. 267, pp. 1-13, 2020.

[19] B. Ke, K. Zhou, C. Xu, H. Deng, J. Li, and F. Bin, “Dynamic mechanical property deterioration model of sandstone caused by freeze-thaw weathering," Rock Mechanics and Rock Engineering, vol. 51, no. 9, pp. 2791-2804, 2018.

[20] Y.-L. Chen, J. Ni, L.-H. Jiang, M.-L. Liu, P. Wang, and R. Azzam, "Experimental study on mechanical properties of granite after freeze-thaw cycling," Environmental Earth Sciences, vol. 71, no. 8, pp. 3349-3354, 2014.

[21] T. Li, X. Pei, D. Wang, R. Huang, and H. Tang, "Nonlinear behavior and damage model for fractured rock under cyclic loading based on energy dissipation principle," Engineering Fracture Mechanics, vol. 206, no. 1, pp. 330-341, 2019.

[22] F. N. Jin, M. R. Jiang, and X. L. Gao, "Defining damage variable based on energy dissi- pation," Chinese Journal of Rock Mechanics and Engineering, vol. 12, pp. 1976-1980, 2004.

[23] J.-Q. Xiao, D.-X. Ding, G. Xu, and F.-L. Jiang, "Inverted S-shaped model for nonlinear fatigue damage of rock," International Journal of Rock Mechanics and Mining Sciences, vol. 46, no. 3, pp. 643-648, 2009. 